\title{
Survey and analysis of resource of Beijing Niu Jie food culture
}

\author{
Zhao Qun ${ }^{1,2,3, ~ a}$, Chen Zhongzhao, b \\ ${ }^{1}$ Department of landscape architecture, Beijing University of Agriculture, Peking,Beijing 102206,China \\ ${ }^{2}$ Beijing Rural Landscape Planning and Design Engineering Technology Center, Peking, Beijing \\ 102206, China \\ ${ }^{3}$ Beijing Laboratory of Urban and Rural Ecological Environment, Peking ,Beijing 100083,China \\ a869574897@qq.com, bchenzhongzhao@bua.edu.cn
}

Keywords: Niu Jie, food tourism, survey and analysis.

\begin{abstract}
Beijing has a long history; food culture is unique. Every day will attract tens of thousands of Chinese and foreign tourists to Niujie tasting food. Due to the influence of religious culture, many Arab countries of the tourists will be attracted, by eating Chinese food to experience the profound Chinese food culture. This has greatly promoted the cultural exchanges between China and people of all of the world, and deepened the friendly relations. In the diet culture and tourism industry blend with each other and under the background of the rapid development, in terms of Beijing Niujie such food destinations, how to understand and Niujie cooking cultural resources evaluation, to the Niujie diet culture resources to make a rational analysis, put forward the development principle, development strategy and specific diet culture tourism products are very significant. It has certain practical significance and value to make the food culture tourism resources into the special tourism projects, and promote the healthy development of the food culture.
\end{abstract}

\section{Introduction}

With the development of society, mankind has gradually entered the age of automation and intelligence. But people don't forget traditional food. Food tourism, as a new form of tourism, is popular for its pursuit of visual and taste. Niu Jie food is famous. It is rich in variety, distinctive and delicious. Every year It attract a large number of tourists of China and abroad to visit and taste on the tip of the tongue, greatly stimulated the development of the local food and beverage industry, drive the related industrial economic growth. But the development of cow street food tourism is not yet mature and there are some problems. Therefore, the investigation and research on the tourist food of Niu Jie are carried out, and some reasonable Suggestions are put forward.

\section{The concentration analysis of expectations}

Through the survey of 300 tourists, the data was analysed by using SPSS software. 
Table 1 tourists' focus on the expectation of the factors of the influence of food tourism in Niu Jie

\begin{tabular}{|c|c|c|c|c|c|c|c|}
\hline \multirow{2}{*}{ variable factor } & \multicolumn{2}{|c|}{$\mathrm{N}$} & \multirow{2}{*}{ mean } & \multirow{2}{*}{ median } & \multirow{2}{*}{ Divergence } & \multirow{2}{*}{ Kurtosis } & \\
\cline { 2 - 7 } & effective & missing & & & & \\
\hline Taste expectations & 300 & 0 & 4.51 & 4 & -0.301 & 0.365 & \\
\hline Amount expectations & 300 & 0 & 3.67 & 4 & -0.286 & -0.221 & \\
\hline Characteristics & 300 & 0 & 3.14 & 3 & 0.365 & 0.554 & \\
\hline Kinds expectations & 300 & 0 & 3.88 & 4 & 0.621 & -0.458 & \\
\hline Nutritional & 300 & 0 & 4.02 & 4 & -0.52 & 0.623 & \\
\hline Freshness & 300 & 0 & 4.21 & 4 & 0.326 & -0.365 & \\
\hline Health conditions & 300 & 0 & 4.45 & 4 & -0.562 & 0.482 & \\
\hline Quality of service & 300 & 0 & 3.92 & 4 & 0.368 & -0.624 & \\
\hline Environment & 300 & 0 & 3.21 & 3 & 0.605 & -0.12 & \\
\hline Entertainment & 30 & 0 & 3.11 & 3 & -0.284 & 0.321 & \\
\hline Production performance & 310 & 0 & 3.15 & 3 & 0.268 & 0.125 & \\
\hline Eating utensils & 300 & 0 & 3.58 & 3 & -0.752 & -0.221 & \\
\hline Menu expectations & 300 & 0 & 3.09 & 3 & 0.623 & 0.009 & \\
\hline Parking space & 300 & 0 & 3.25 & 3 & 0.258 & 0.621 & \\
\hline Dinner time & 300 & & 4.22 & 4 & 0.603 & -0.521 & \\
\hline
\end{tabular}

Based on the results of table 1 , the results showed that the mean, median, and number of concentrations were not very different, and the central tendency was obvious. Depending on the size of the expected value, you can divide the visitor into two levels, which is less than or equal to the average of 3, which means that visitors are less concerned about this factor. $4<$ mean is less than or less than 5 , which means that visitors should pay more attention to this factor. So The first category is the food taste, nutritional value, freshness, hygiene and meal time. The second category of factors for tourists less, culinary weight, food characteristics, types of food, service quality, store environment, entertainment, production performance, eating utensils, menu, presence of parking Spaces. Overall, the expected difference in expectations of Niu Jie diet was significant.

\subsection{Tourist satisfaction and discrete analysis of Tauren food}

Table 2 Analysis of central tendency of satisfaction

\begin{tabular}{|c|c|c|c|c|c|c|}
\hline \multirow{2}{*}{ variable factor } & \multicolumn{2}{|c|}{$\mathrm{N}$} & \multirow{2}{*}{ mean } & \multirow{2}{*}{ median } & \multirow{2}{*}{ Divergence } & \multirow{2}{*}{ Kurtosis } \\
\cline { 2 - 6 } & effective & missing & & & & \\
\hline Taste expectations & 300 & 0 & 4.08 & 4 & -0.211 & 0.256 \\
\hline Amount expectations & 300 & 0 & 3.32 & 3 & -0.451 & 0.315 \\
\hline Characteristics & 300 & 0 & 3.68 & 4 & -0.589 & -0.215 \\
\hline Kinds expectations & 300 & 0 & 3.75 & 4 & -0.231 & -0.009 \\
\hline Nutritional & 300 & 0 & 3.25 & 3 & -0.312 & -0.265 \\
\hline Freshness & 300 & 0 & 3.98 & 4 & -0.152 & -0.259 \\
\hline Health conditions & 300 & 0 & 3.56 & 3 & -0.684 & -0.384 \\
\hline Quality of service & 300 & 0 & 3.36 & 3 & -0.264 & -0.157 \\
\hline Environment & 300 & 0 & 3.26 & 3 & -0.029 & -0.245 \\
\hline Entertainment & 300 & 0 & 3.21 & 3 & 0.068 & 0.584 \\
\hline Production performance & 300 & 0 & 3.35 & 3 & -0.452 & -0.125 \\
\hline Eating utensils & 300 & 0 & 3.62 & 4 & -0.445 & -0.564 \\
\hline Menu expectations & 300 & 0 & 3.65 & 4 & -0.268 & 0.358 \\
\hline Parking space & 300 & 0 & 3.18 & 3 & -0.005 & -0.254 \\
\hline Dinner time & 300 & 0 & 3.11 & 3 & 0.089 & -0.114 \\
\hline
\end{tabular}

According to the results in table 1 Tourist satisfaction to Niu Jie food tourism mean lies between 3.11 to 4.08, which can be divided the satisfaction of the influence factor into two levels, namely the average $\geqq 3.5$, says visitors to various factors affecting the degree of satisfaction is higher. 3.1 $<$ mean $<3.5$ indicates that the tourists are less satisfied with the affected factors. Average 
according to the descending order the tourists' satisfaction degree, and tourist satisfaction better factors are: food taste, freshness and production of special types of food, food, menu, eating utensils, diet. Poor tourist satisfaction factors: service quality, production performance, a food portions, store environment, nutritional value, entertainment, parking, meal time. Overall, the satisfaction of tourists also showed greater concentration. Unfortunately, there is a gap in satisfaction, so there is a lot of room for improvement.

\subsection{T test analysis of visitor expectations and satisfaction}

Table $3 \mathrm{~T}$ test analysis of visitor expectations and satisfaction

\begin{tabular}{|c|c|c|c|c|c|c|c|c|}
\hline variable factor & mean & $\begin{array}{c}\text { standard } \\
\text { deviation }\end{array}$ & $\begin{array}{c}\text { Standard error } \\
\text { of mean }\end{array}$ & $\begin{array}{c}\text { lower } \\
\text { limit }\end{array}$ & $\begin{array}{c}\text { Upper } \\
\text { limit }\end{array}$ & $\mathrm{t}$ & $\mathrm{df}$ & $\mathrm{sig}$ \\
\hline Taste & 0.43 & 0.845 & 0.058 & 0.352 & 0.563 & 9.102 & 299 & 0.000 \\
\hline Amount & 0.35 & 0.958 & 0.049 & 0.285 & 0.452 & 7.523 & 299 & 0.001 \\
\hline Characteristics & -0.54 & 0.775 & 0.063 & -0.485 & -0.653 & - & 299 & 0.538 \\
\hline Kinds & 0.13 & 0.952 & 0.045 & 0.010 & 0.276 & 2.956 & 299 & 0.000 \\
\hline Nutritional & 0.77 & 0.806 & 0.062 & 0.072 & 1.328 & 16.230 & 299 & 0.000 \\
\hline Freshness & 0.23 & 0.920 & 0.056 & 0.185 & 0.453 & 4.865 & 299 & 0.000 \\
\hline $\begin{array}{c}\text { Health } \\
\text { conditions }\end{array}$ & 0.89 & 0.836 & 0.040 & 0.658 & 0.952 & 18.379 & 299 & 0.613 \\
\hline $\begin{array}{c}\text { Quality of } \\
\text { service }\end{array}$ & 0.56 & 0.726 & 0.061 & 0.410 & 0.625 & 10.358 & 299 & 0.216 \\
\hline Environment & -0.05 & 0.994 & 0.057 & -1.02 & 0.155 & -1.650 & 299 & 0.000 \\
\hline Entertainment & -0.1 & 0.850 & 0.046 & -0.056 & -0.064 & -1.832 & 299 & 0.000 \\
\hline $\begin{array}{c}\text { Production } \\
\text { performance }\end{array}$ & -0.2 & 0.758 & 0.062 & -0.182 & -0.135 & -3.703 & 299 & 0.003 \\
\hline Eating utensils & -0.04 & 0.842 & 0.049 & -0.155 & -0.061 & -0.856 & 299 & 0.000 \\
\hline $\begin{array}{c}\text { Menu } \\
\text { expectations }\end{array}$ & -0.56 & 0.963 & 0.050 & -0.521 & -0.712 & - & 299 & 0.000 \\
\hline Parking space & 0.07 & 0.778 & 0.063 & -0.061 & 0.084 & 1.215 & 299 & 0.491 \\
\hline \begin{tabular}{c} 
Dinner time \\
\hline
\end{tabular} & 1.11 & 0.807 & 0.049 & 0.884 & 1.253 & 23.125 & 299 & 0.000 \\
\hline
\end{tabular}

Using the matching sample $\mathrm{T}$ test to analyse the difference between the expectation and satisfaction of the tourists participating in Niu Jiet food tourism. According to table 3, according to the characteristics of food, fresh degree, health status, presence of parking Spaces are paired Sig value is greater than 0.05 , other factors are less than 0.05 , so that the satisfaction of the expectations of the four factors and the difference is not obvious, but other factors are obvious differences. The value of $\mathrm{T}$ is less than zero, which means that visitors have low expectations and high levels of satisfaction. The other nine values of t-value greater than zero indicate that the visitor is disappointed. The value of nutrition, hygiene, quality of service, and the t-value of the meal time were greater than 1 , which means that the tourists were more disappointed.

\section{Suggestions for the development of Niu Jie food tourism}

In the analysis of the matching sample $\mathrm{T}$ test, visitors were most disappointed in the time of the meal. It is often a long time for people to wait in line at a few hot restaurants. This damage the image of Niu Jie in the invisible. So some restaurants can be advised to upgrade and upgrade the reception level. 


\subsection{Improve the quality and class of the meal}

With the improvement of people's living standard, more and more people pursue the quality of food and beverage. The restaurant should not only be good and hygienic, but also have a good dining environment and exquisite product packaging. Today, most of the outside selling food in Niu Jie is packaged with simple plastic bags, which has influenced the image of Niu Jie. In the analysis of the central tendency of tourist satisfaction, the factors of the poor visitor satisfaction were the store environment and the quality of service.

\subsection{Fully explore the cultural connotation}

Although tourists are more satisfied with the variety of food and menus. But they were less satisfied with entertainment and performance. So the restaurant should add something to the production, entertainment and so on. Prominent Islamic culture is to attract more tourists. Also pick up some traditional old Beijing Niu Jie snacks, such as buckwheat cake, mung bean noodles made of mung bean, rice noodle cake, etc.

\section{Conclusion}

Through the investigation and analysis, obtained the customer of Niu Jie expectation and satisfaction, expectation value trend, satisfaction trend is consistent, for the development of Niu Jie food tourism provides a reliable basis.

\section{References}

[1]. Hall CM, Sharpies L, Mitchell R, et al. Food Tourism around the World [M], Oxford: Butterworth Heinemann. 2003:1-25.

[2]. Kivela \& Crotts J C. Tourism and gastronomy; Gastronomy's influence on how tourists experience a destination [J]. Journal of Hospitality \& Tourism Research, 2006, 30(3):354-377

[3]. Long, L. Lexington, Kentucky: The University Press of Kentucky [J]. Culinary tourism.2004.

[4]. Quan, S, Wang, N. Towards a structural model of tourist experience: an illustration from food experiences in tourism [J]. Tourism Management,2004,25(3):296-304

[5]. Cela A, Lankford J, Lankford S. Local food festivals in Northeast Iowa communities; Avisitor and economic impact study [J]. Managing Leisure, 2007,12 (2); 171 -186.

[6]. SmithS, Costello C. Segmenting visitors to a culinary event: Motivations, travelbehavior, and expenditures [J] Journal of Hospitality Marketing \& Management,2009,18 (1):44 -67.

[7]. Zhangcailei. Chinese food tourism [M]. Foreign economic and trade university press,1998.

[8]. Wengyi. Evaluation and development of hunan food tourism resource [J]. Journal of hunan business school, 2008, No.4.

[9]. Yangdapeng, Yunnan food tourism development research [D]. Master's thesis of Yunnan University,2007.

[10]. Zhangyuan. Chengdu food tourism research [D]. Master's thesis of Fudan University,2008.

[11]. Zhoushuyun. Talk about the development of Shandong food tourism [J]. Modern shopping mall,2009 (9):105.

[12]. Wuxiaodong. The development of food tourism in China is based on leisure economy [J]. Tourism economic research,2010 (9):136-138.

[13]. Wangliuliu. The development of food culture and tourism [J]. Chinese cooking study,1997, (4):59-61. 
[14]. Wangxiaowen. The tourism development of the cultural resources of catering culture is taken as an example in Fuzhou [J]. Journal of Fujian normal university,2001, (3).

[15]. Yangli. To analyze the development of food culture tourism resources [J]. Academic exploration, 2001, (6).

[16]. Yangli. Try to analyze the characteristics of food culture [J]. Yunnan geography environmental research,2001, (9). 